\title{
Design of Nutritional Status System for Stunting Early Prevention
}

\author{
Niyalatul Muna* \\ Department of Health \\ Politeknik Negeri Jember \\ Jember, Indonesia \\ niyalatul@polije.ac.id
}

\author{
Ervina Rachmawati \\ Department of Health \\ Politeknik Negeri Jember \\ Jember, Indonesia \\ ervina_rachmawati@polije.ac.id
}

\author{
Ida Nurmawati \\ Department of Health \\ Politeknik Negeri Jember \\ Jember, Indonesia \\ ida@polije.ac.id
}

\begin{abstract}
Based on the Electronic Community-Based Nutrition Recording and Reporting (e-PPGBM) as of July 20, 2019, it shows that the prevalence of stunting in East Java has increased. One district that has a high stunting rate in East Java is Jember Regency. In Jember Regency, 2017, the prevalence of stunting was recorded at $17.73 \%$ or as much as 29,020 children under five. The causes of stunting can be started from nutritional status, from the process of fetal growth and development in the womb to a child aged 2 years. This process is influenced by the physical condition and health of the mother during adolescence. To prevent this, technology can be applied as a medium of education, information, monitoring, or stunting prevention screening. Therefore, this study aims to design a system that can screen the nutritional status of young women, pregnant women, nursing mothers, infants, and toddlers. The system stores data on the results of medical examinations (user history), reports user records and provides advice or education on the results of records that have been carried out in the system. The input variables used were data on examination results and nutritional status in accordance with stunting management standards. The system designed by researchers use the Prototype system development method. The system was designed to be called the Web-Based Early Stunting Prevention Application (STEP-A). The system designed has been accepted and running well. The system has been able to provide health solutions related to nutritional status that has been inputted according to health standards.
\end{abstract}

Keywords - nutritional status, prototype, stunting

\section{INTRODUCTION}

One of the nutritional problems experienced by toddlers in the world today is stunting. According to WHO, Indonesia is the third highest prevalence country in Southeast Asia with an average prevalence of stunting under five in 2005-2017 of $36.4 \%$ [1]. East Java Province is one of the provinces that has a higher stunting prevalence rate than the national rate. Based on Basic Health Research Data (Riskesdas) in 2018, the prevalence of stunting in children under five in East Java Province, $32.81 \%$ [2].

The start of stunting cases begins with the pre-conception period in expectant mothers (young women) who experience malnutrition and anaemia. In 2017, the percentage of young women with short and very short conditions increased from the previous year, namely $7.9 \%$ very short, and $27.6 \%$ short. If the nutrition of young women is not improved, there will be more and more expectant mothers who have short stature and
/ or lack of chronic energy. This will have an impact on increasing the prevalence of stunting in Indonesia [3].

According to the 2017 Census data, almost half of women pregnant in Indonesia have their first pregnancy at a young age or adolescence. The nutritional problems in pregnant women in Indonesia, namely height $<150 \mathrm{~cm}$ by $31.3 \%$, risk of KEK $24.2 \%$, and anemia of $37.1 \%$. It has an impact on babies who are malnourished, with low birth weight (LBW) $<2,500$ grams and also a long body that is less than $48 \mathrm{~cm}$. LBW infants account for approximately $20 \%$ of the incidence of stunting [4].

The occurrence of stunting is the impact of prospective pregnant women (young women) who are malnourished, followed by pregnant and lactating women who are also problematic, improper parenting for babies and toddlers (IMD failure, failure of exclusive breastfeeding, inadequate complementary feeding. right, and failing to wean prematurely). Based on the background, it can be seen that the problem of stunting in Indonesia is multi-dimensional. There is still little research on the use of ICT in efforts to prevent stunting. Previous research has discussed the risk factors for stunting [5], and there are also studies that discuss prediction algorithms that detect the risk of stunting in early childhood [6] [7].

Therefore, this study designed a website-based early stunting prevention system design for young women, pregnant women, breastfeeding mothers, infants, and toddlers. The research was conducted to design and record nutritional status applications that can be controlled by the user as a means of education, information, and self-screening.. The method used in system development a prototype. The prototype method in the study will has be adjusted to the needs of users and experts who provider input in recording nutritional status as a factor in the cause of stunting so that the screening is easy. The nutritional status of the system to be designed is called the Stunting Early Prevention System Application (STEP-A). The input variable in the system adjusts the nutritional status history that has been adjusted to the health standard. The output that has been designed produces an output in the form of a medical history regarding the nutritional status experienced by the user and solutions to overcome problems according to their level. The solutions provided are directly linked to health information on the website menu. 


\section{RELATED WORKS}

Malnutrition in children under five is still widely prevalent in the world. It is the focus of numerous research works and of numerous public health interventions. Child malnutrition is primarily defined by anthropometric indicators, in reference to international growth standards elaborated in populations free of malnutrition. These anthropometric indicators describe the various dimensions of child growth in particular linear growth (bones), fat, and muscle. The aetiology of malnutrition is complex, as nutritional status is the product of numerous interactions between food intake, disease, metabolism, immunity, and endocrine system. Of particular importance for lower - and - middle - income countries (LMIC) is the well - documented synergistic effect of nutrition and infection.

Research by experts shows that all nutritional problems for children (short, fat, PTM) begin with the development of the fetus in the womb until the child is 2 years old. Lack of nutrition can interfere with the process of growth and development, resulting in deformities in the short stature, even though the genes in cells show the potential to grow normally [8][6]. The process of fetal growth and development is influenced by the physical condition and health of the mother during adolescence. For this reason, efforts to prevent fetal growth and development disorders until the age of 2 years are focused on pregnant women, children 0-23 months, and premarital girls, as a group of the first 1000 days of life [9].

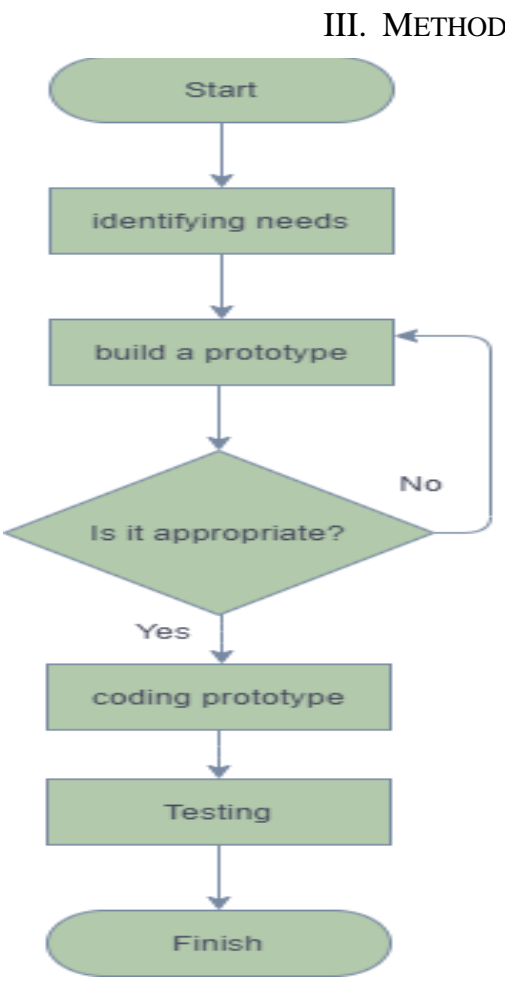

Fig. 1. Research Flowchart Design of Nutritional Status System

The steps in general in the research can be seen in Fig 1. The flow of this research used the software system development method (Application Development) using the Prototype model, which consists of listening to the user or the opinions of experts regarding the system being built. At this stage, identification of needs was carried out by analyzing what needs to be applied to the system.

In this stage, the researcher begins to design and build a prototype first, then the results could be immediately asked back to the user or experts regarding the prototype before coding and testing was carried out [10]. So that, it has been corrected immediately first if something was still not suitable.

\section{A. Needs Analysis}

At this stage, it was necessary to determine the requirements that competable in the application to be made. The requirement that was obtained will has be the system functionality of STEP-A. Functional requirements contain various functions that can later be performed by the system that was made directly. Non-functional requirements were those needed by software for needs outside the main function of a system as a support for the program to run properly.

Functional Requirements:

a. Admin access rights can manage the STEP-A Website

b. Admin access rights can edit or update and delete data on the main website page

c. Admin access rights can view website visit data, user data, user history data, and user reports

d. Admin access rights can fill in, edit, delete personal data

e. User access rights can change or edit the account (username, email or password).

f. User access rights can manage profile data (entry and edit personal data)

g. User access rights can manage historical data from adolescents, pregnancy, and infant data (entry and edit history data)

h. User access rights can see the solution given from the results of historical data entry (the solution will provide a link in health information).

i. Access rights Users can view reports on the results of historical data entry (In the baby menu can display charts of KMS development)

Non-Functional Requirements: Requirements to make the STEP-A system operationally run in all operating systems on laptops, tabs/tablets, and Smartphones that have browsers (Software to open web pages), and minimum memory requirement of 2 GB RAM. Have a data plan or connect to an internet network. In Security, it is equipped with a password for the STEP-A system and its database. Information is used to inform the health history and solutions to the nutritional status results that have been filled in by the user. It is used to inform the success of creating an account at STEP-A and the login page of the user, it is used to inform the main page of STEP-A, is used to display a graph of the development of infants, is used to display information related to stunting, and is used to inform if the password is entered by the wrong user.

\section{B. Design Prototype}

The system description to be built starts from the main page of the Stunting Early Prevention Application (STEP-A). On the main page, information regarding the STEP-A 
application will be given and a menu or link containing the user manual book which can be accessed by all website page visitors before registering for an account. After that, there is a list of accounts (user accounts) which is used to register before accessing the application. Every user (user) is required to have an account first because this application will record history or examination results which will be stored as monitoring data for stunting prevention from an early age. If the user has registered an account, he can directly access the application by entering via the login menu. After the user has successfully logged in with his account, there will be a Home Menu, Dashboard, Teenagers, Pregnancy, and Babies.

Menus that are made based on the type will has contained data on the results of medical examinations or user history related to the nutritional status which is used as a reference for identifying stunting problems. The data entered in the application will has be adjusted to the stunting management program and health guidelines. The results of recording history by the user will has be used as a reference to provide advice and education that could be given to the user as a control of the user's health status to prevent stunting. system overview can be seen in Fig. 2

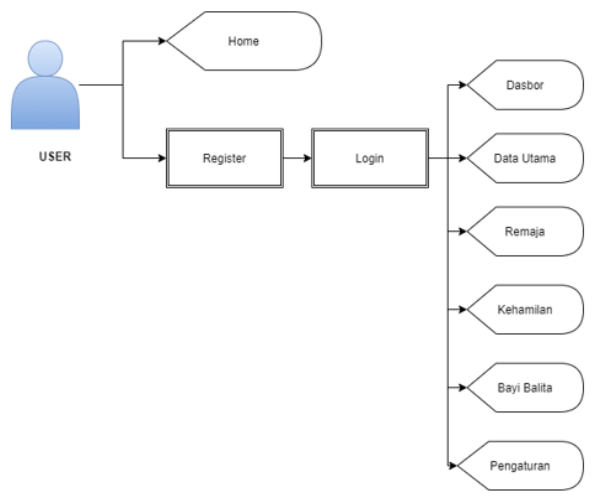

Fig. 2. Map Menu Design of Nutritional Status System (User)

User permissions can directly visit the website page and see the home page screen or menu. Users can enter the user page if they have registered first on the system, they can log in according to the account registered at the time of registration. After logging in, the user will enter several user pages, namely the dashboard, main data, teenagers, pregnancy, babies, and settings. Each page can be managed by the user itself. System overview can be seen in Fig. 3

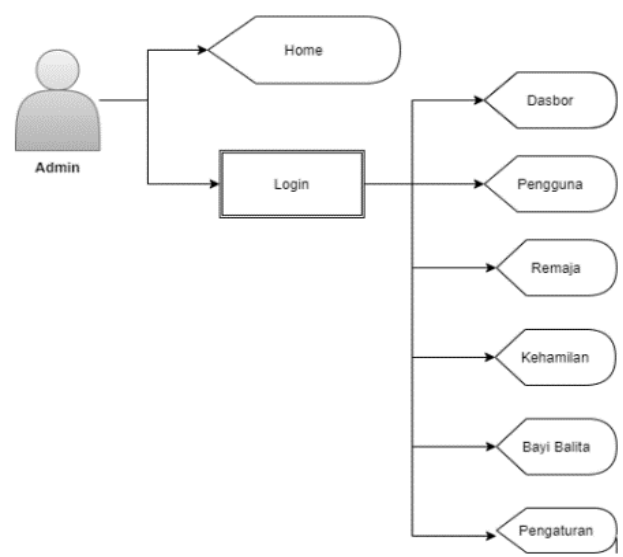

Fig. 3. Map Menu Design of Nutritional Status System (Admin)
Admin access rights can manage the website and view the data that is authenticated on the STEP-A website. Admin can assist in the process of updating and maintaining the website. Admins can directly log into the admin page and see the main view (home). Admin access rights directly login.

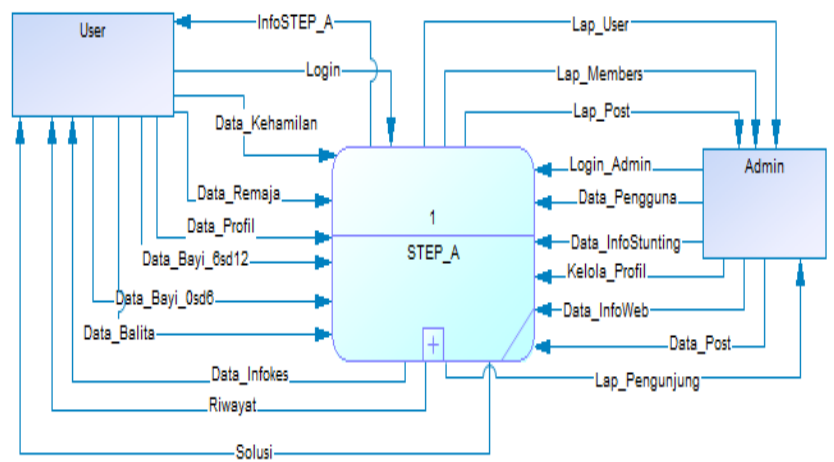

Fig. 4. Diagram Contex Design of Nutritional Status System

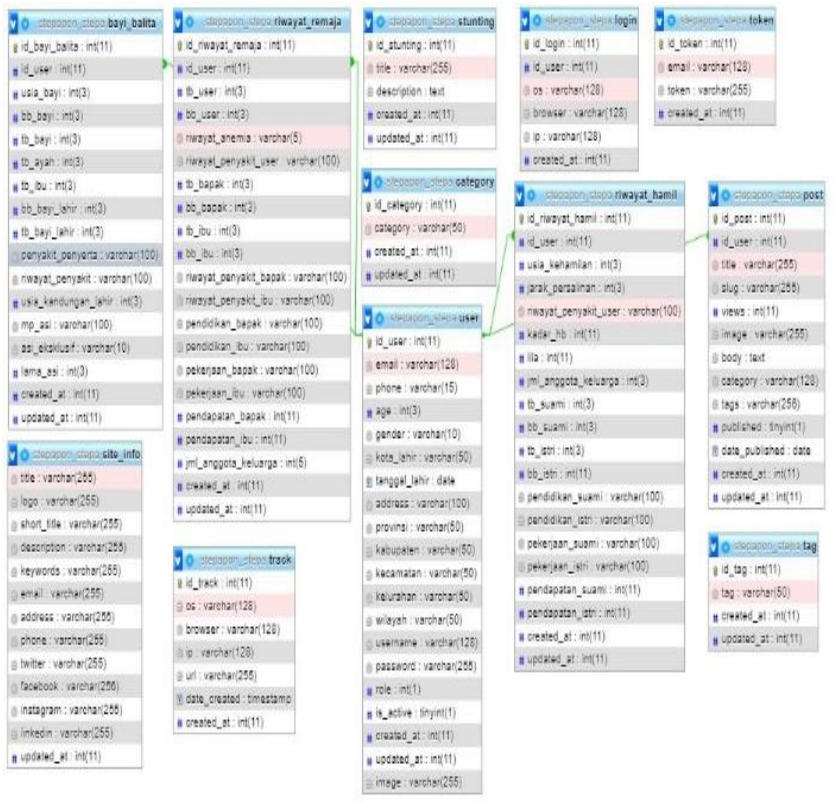

Fig. 5. Database Design of Nutritional Status System

The overall running system can be seen from the DFD design with a context diagram or DFD level 0 which can be seen in Figure 4. 2 entities are owned, namely user and admin. Each entity has different data entry and exit path.

The database design of the system being built can be seen in Figure 5. The master table consists of 8 tables and 4 transaction tables. The master table consists of the User, Login, Stunting, token, category, track, tag, and site info tables. Transaction tables that have relations between tables consist of history_adolescent, pregnancy history, infant_member, and post tables. Relationships between tables that occur, users can fill in personal data once in the medical history and fill in several medical histories.

\section{EXPERIMENTAL RESULTS}

Prototype coding was made based on a web framework with several views to be able to fill in the history and nutritional status of users who have registered and have an 
account. The test was conducted with 10 users for the initial stage as testing before STEP-A could be implemented.

In Fig. 6 is a page that contains the main page of the homepage step-a, where on this page contains a menu of health information, registration, login and stunting F.A.Q. every visitor who accesses the STEP-AURL will has be open this page. This page is made user friendly, making it easier for users to use this system.

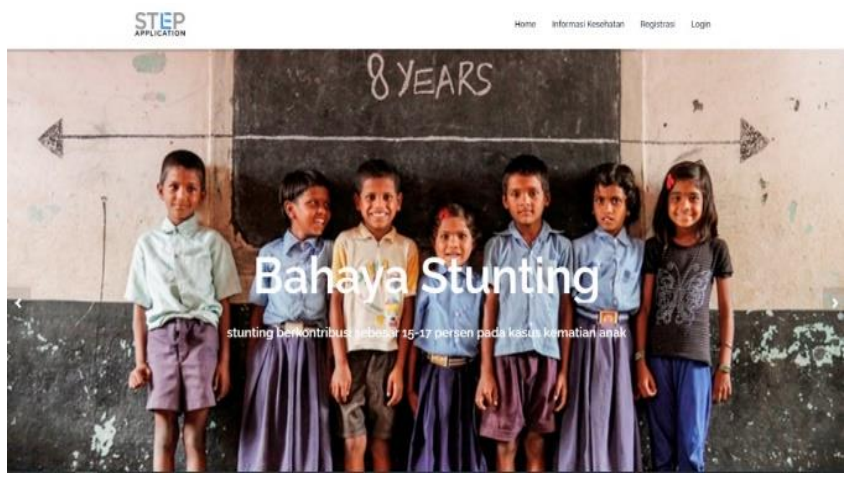

Fig. 6. Design of Nutritional Status System (Home)

In Fig.7 is the registration page for new users who do not have an account, what must be entered on this page is the user's full name, user phone number, password and validation password. After the user enters this registration form, the user Adolescent of menu access page.

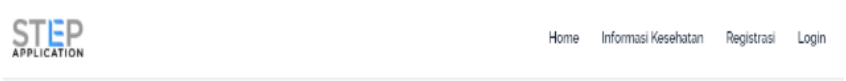

Welcome to STEP APPLICATION

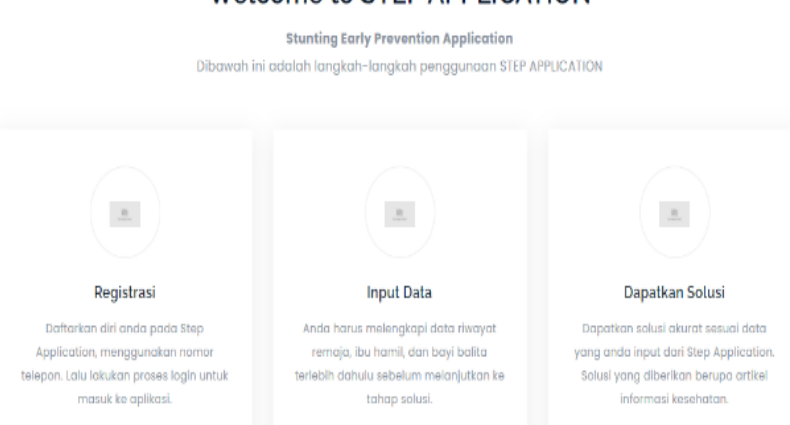

Fig. 7. How to user of Nutritional Status System (Home)

Figure 8 contains data pages for adolescent data, which contains adolescent history data, namely height, weight, user's disease history, father's height, father's weight, mother's height, maternal weight, history of father's disease, history of maternal disease, father's education, mother's education, mother's occupation, father's job, father's income, mother's opinion, number of family members. There is also a BMI menu and a history of anemia.

Figure 9 is a page for pregnancy history which contains pregnancy history data, namely gestational age, delivery distance, history of illness during pregnancy, HB level, LILA, number of family members, husband's height, husband's weight, wife's height, wife's weight, husband's education, education. wife, husband's job, wife's job, husband's income, wife's income. There is also a history of anemia and KEKI.

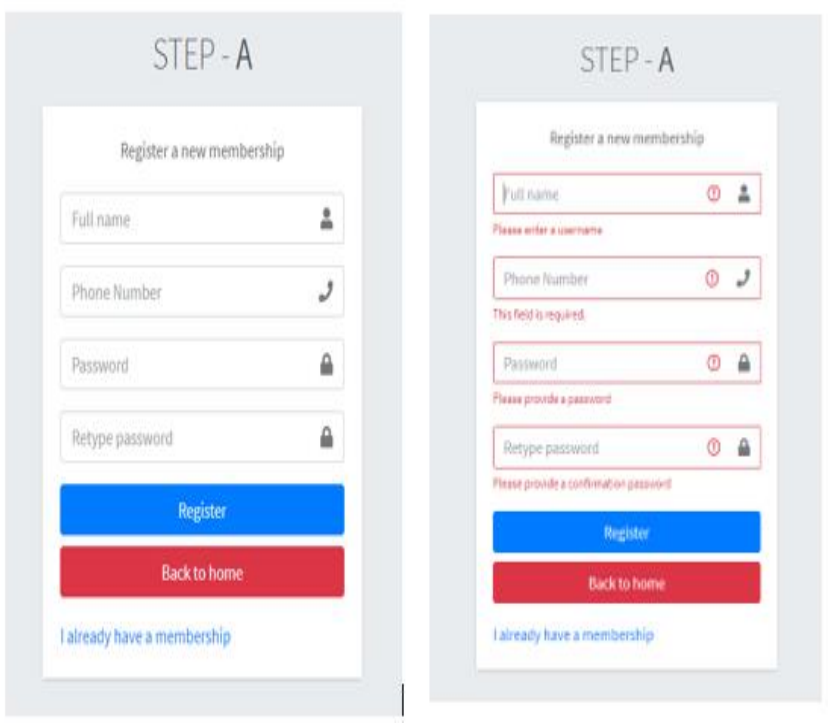

Fig. 8. Register Page for new user

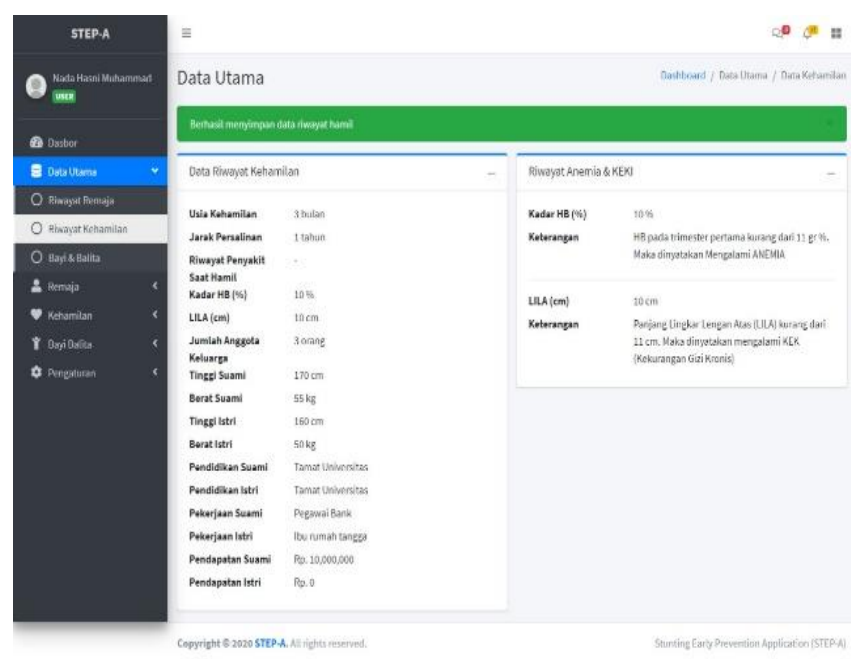

Fig. 9. Pregnancy of menu access page

Figure 10 is a data page for infants under five, which contains data on the current age of the baby, current baby weight, current baby height, father's height, mother's height, baby weight at birth and height at birth, including comorbidities, history of disease, gestational age at birth and whether exclusive breastfeeding includes complementary foods.

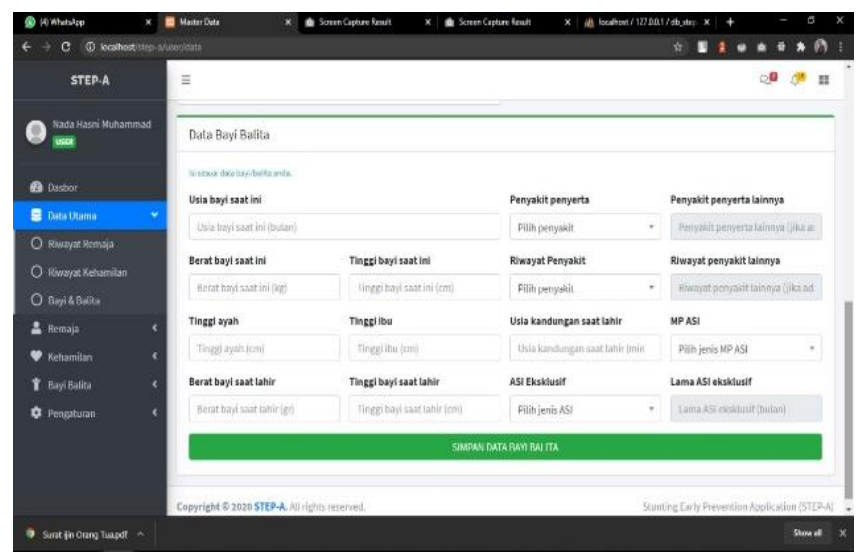

Fig. 10. Babies of menu access page 
The STEP-A system has been tested with the black box testing method, including the tested menu, scenario, expected results and conclusions. The first menu to be tested was the login menu with the scenario of entering a username and password while the expected result was being able to log into the admin and user pages, while the conclusion of this test was a successful. Furthermore, the registration menu was tested by enrying the registration data for the full name, telephone, password and password retry. The result obtained during the test was that it could have saved the data entered with a notification register. Furthermore, the expected result was that the home menu provides information regarding step-a and displays the main page of the website, while when testing the home menu could be appear successfully legible and according to the menu link.

Furthermore, testing is carried out on the user profile menu, the method of testing was done by editing and completing the user profile data and the results after testing the system can save, edit and save user data. Furthermore, the admin profile menu, the scenario was that you could have edit and complete the admin profile, while testing could be successfully edit and save admin profile data. Then, the admin dashboard menu on this menu functions to provide visitor information, browser and device, latest member, recent post and login. After testing, the system can display visitor information, browser and device, latest member, recent post and login. The next test was the user menu, where the admin menu adds and manages users who register for a STEP-A account. The result after testing, the system could have added updates, entries, save, and, delete user data. Furthermore, testing the settings menu where the admin manages profile data, stunting information and website information. The results of the system testing could be successfully manage data editing, entry, deleting profile data, stunting information, and website information. The last menu was the logout menu where this menu contains the process of exiting user or admin access rights, after testing the user has been exited the system.

\section{CONCLUSION}

Research on early stunting prevention systems from adolescence, pregnancy, infants, and toddlers on the webbased Stunting Early Prevention Application (STEP-A) has now been designed and made according to a needs analysis with access rights owned by the system, namely users or users in general, and the admin who will manage STEP-A. The STEP-A prototype design that was built consisted of a user and admin system flow design, context diagram (DFD level 0 ), and ERD that had been realized with 2 entities, and 12 tables in 1 MySQL database. Prototype coding has been built to test pre-made designs based on a web framework. The STEP-A test which was run and carried out using the blackbox method was already running well. STEP-A has been accepted at the Jelbuk Community Health Service Center as one of the trial samples.

\section{ACKNOWLEDGMENT}

The authors would like to thank Politeknik Negeri Jember for the research funding through PNBP number: 474 / PL17.4 / PG / 2020.

\section{REFERENCES}

[1] WHO, "Stunted Growth and Development," Geneva, 2017.

[2] Kementerian kesehatan RI, "Basic Health Research," 2019.

[3] Kementerian kesehatan RI, "The Situation of Short Toddler (Stunting) in Indonesia," Buletin Jendela Pusat Data dan Informasi Kemenkes RI, ISSN: 2088-270X., Jakarta, 2018.

[4] Badan Pusat Statistik, "National Socio-Economic Survey (Susenas) 2016," Jakarta, 2017.

[5] C. R. Titaley, I. Ariawan, D. Hapsari, A. Muasyaroh, and M. J. Dibley, "Determinants of the stunting of children under two years old in Indonesia: A multilevel analysis of the 2013 Indonesia basic health survey," Nutrients, vol. 11, no. 5, 2019.

[6] S. Hanieh et al., "The Stunting Tool for Early Prevention: Development and external validation of a novel tool to predict risk of stunting in children at 3 years of age," BMJ Glob. Heal., vol. 4, no. 6, pp. 1-12, 2019.

[7] F. L. Afriansyah, E. M. Yuniarno, and M. H. Purnomo, "A Novel Approach on Classification of Infant Activity Post Surgery Based on Motion Vector," pp. 213-218, 2017.

[8] Irmawati, "Prediction Model and Scoring System in Prevention and Control of Stunting Problems in Under Five-Year-Olds in Indonesia," J. Kesehat. Masy., vol. 4, no. 1, pp. 43-47, 2018.

[9] WHO, "WHO Global Nutrition Target: Stunting Policy Brief," Geneva, 2014.

[10] R. N. Karimah and A. P. Wicaksono, "Prototype of Information System for Newborn Baby Services in Primary Health Facilities," khazanah informatika pp. 16-20, 2018. 